\title{
Direitos humanos, violência, moradia: dignidade ameaçada
}

\author{
Irismar Sousa de Menezes
}

Pedagoga e Especialista em Direitos Humanos

Colégio Nossa Senhora do Rosário - São Paulo

irismarop@hotmail.com

Solange Martins Oliveira Magalhães

Doutora em Educação

Professora da UFG

solufg@hotmail.com

\begin{abstract}
Resumo Os direitos humanos na sua natureza e universalidade estão profundamente ligados à essência do ser humano. Eles valem para todas as pessoas, até mesmo para o planeta. A Declaração dos Direitos Humanos (DUDH) legitima os direitos humanos na tentativa de assegurar justiça social. O direito à moradia também está consagrado na DUDH; nas Convenções e Constituição Federal do Brasil (1988), em âmbito nacional; no Ministério das Cidades e no Estatuto da Cidade, no estatal; todos garantem à pessoa, na forma da lei, o direito à moradia digna. Entretanto, no dia-a-dia, a realidade é bem diferente, milhões de pessoas vivem em relações conflituosas com o poder público, gerando transtornos e massificação da desigualdade social.
\end{abstract}

Palavras-chave: direitos humanos; violência; exclusão social; ação religiosa; democratização.

\section{Introdução}

Muitas vezes nós moramos em algum lugar muito diferente do que queríamos morar. [...] Enquanto você chora querendo se mudar, milhões de pessoas morrem por não ter onde morar. Enquanto você sonha em desfilar na passarela, o maior sonho de um pobre é morar na favela. Moradia. Diaa-dia mais difícil [...] Sacrifício, cada vez mais (Banda Elipse 2008) ${ }^{1}$.

MÚSICA DA BANDA ElIPSE nos (re-)significa uma verdade: Favela
Boqueirão. Local onde o direito à moradia, assim como todos os
outros direitos, deixa de ser fundamental para as pessoas. Se sem moradia
o ser humano vê-se ferido em sua dignidade, vamos refletir sobre a viola-
ção desse direito e a vida das pessoas da favela Boqueirão, São Paulo.
É sobre essa verdade que a epígrafe nos fala. Com a canção em es-
tilo roque nacional, Moradia, a banda relata que o maior sonho do pobre
é ter uma moradia, mesmo que seja na favela. Parece-nos que a moradia
assume contornos de ser o melhor ambiente para as amizades, para as
relações afetivas, referência para a família; e por ser tão importante
torna-se uma das exigências para a consolidação de uma sociedade mais
justa, solidária, fraterna e sustentável.

1 Fonte: http:/letras.terra.com.br/banda-elipse/1156030. Acesso em: 11 de março de 2008. 
Gadotti (2007, p. 13) descreve as experiências do Fórum Social Mundial ${ }^{2}$, tentando traduzir os caminhos possíveis para a articulação de um novo projeto de sociedade. Entre tantas propostas a serem implantadas, ação que o autor define como sendo altermundialismo, fica-nos clara sua intenção de que o caminho para a transformação da sociedade conclama inevitavelmente o respeito à Declaração Universal dos Direitos Humanos (DUDH), o que inclui o direito à moradia.

$\mathrm{Na}$ cidade de São Paulo, há milhões de pessoas em situação de vulnerabilidade social, em áreas de risco ambiental e social, além de viverem ilegalmente (por necessidade extrema), ainda convivem com exacerbada pobreza e miséria. Sabemos que é por falta de condições que essas pessoas passam a morar em favelas. Essa realidade não difere da do povo que se encontra na Favela Boqueirão, situada num setor considerado de classe média, na região Sul-Ipiranga de São Paulo.

Ela existe há mais de 15 anos em terreno de área pública incluída no perímetro das Zonas Especiais de Interesse Social (ZEIS) ${ }^{3}$. Segundo a Subprefeitura, este espaço ocupado pela favela Boqueirão está no projeto de urbanização e regularização da Subprefeitura.

Se a Subprefeitura pouco investe nos recursos para a população, não é diferente na favela Boqueirão. Lá, não encontramos saneamento básico, o abastecimento de água é irregular e nem sempre ela é tratada pelo órgão responsável, a Companhia de Saneamento Básico do Estado de São Paulo (Sabesp). Quanto à coleta de lixo, os detritos são depositados em lugares impróprios, nas ruas e nos córregos, provocando enchentes e proliferação de vários tipos de doenças. A energia elétrica, por sua vez, não é legalizada: para ter acesso à iluminação, moradores fazem as ligações conhecidas como gatos, arriscando a vida de todos os moradores com a possibilidade de incêndios gerados por curto-circuito. Os barracos são levantados - nas estreitas ruas e nas calçadas - de tijolos, adobe e madeiras, sem nenhum projeto ou segurança estrutural. Ao olharmos para as casas não vemos apenas o direito à moradia violado, mas também a total falta de dignidade humana.

Exemplificando, há na favela um córrego poluído com casas sobre o mesmo, no qual o lixo é jogado por boa parte dos moradores; o esgoto corre a céu aberto e também deságua no rio; não há rede elétrica pública, coleta de lixo, atendimento a saúde, educação etc. Segundo a Subprefeitura, que se faz presente na Secretaria de Assistência à Saúde e Secretaria Municipal de Saúde - Posto de Saúde Familiar (PSF), ali estão cadastradas cerca de 440 famílias, o que corresponde a mais ou menos 1585 pessoas entre crianças, jovens e adultos. Isso significa que nem todos os moradores usufruem os benefícios da Saúde Pública, pois sabemos que ali o número de habitantes é bem maior. Como se não bastasse, falta à favela Boqueirão escola adequada e de qualidade para um crescente número de crianças e adolescentes; trabalho para homens e mulheres que se encontram desempregados e marginalizados; é patente a falta de atendimento para auxiliar no planejamento familiar, além de ausência total de áreas para lazer, entre tantas outras carências.

Cumprindo o trabalho da pastoral social, deparamo-nos com esta dura realidade, mas damos ênfase à negação do direito à moradia. Observamos ao longo dos anos que o provimento dessa necessidade passa pelo empoderamento do espaço físico, conquista da terra, do desejo de vender a quem quer possuir moradia digna e pagamento excessivo pelo acesso aos serviços básicos: água, saneamento, coleta, destino e tratamento de resíduos sólidos, energia elétrica. Se a maioria das pessoas quer efetivar o direito à moradia, outros tantos querem lucrar com a efetivação desse querer.

Beneficia-se do pressuposto de que a habitabilidade satisfatória é necessária para a dignidade humana, mas negligenciam a capacidade de luta dos Movimentos dos Trabalhadores Sem-Teto, Sem-Emprego, SemEducação formal, que tentam, a duras penas, fugir à massificação da desigualdade e dos problemas sociais, tentando possibilitar por várias vias, a efetivação do direito à moradia. Diante disso, não podemos deixar de asseverar a necessidade da valorização da dignidade humana, conforme a Declaração dos Direitos Humanos - que, como se pode perceber, não tem sido honrada pelas instâncias do governo brasileiro.

A favela Boqueirão é, para a pastoral social das irmãs dominicanas, objeto de estudo no que diz respeito à violação do direito a moradia, bem como a falta de infra-estrutura do local; a interferência nos conflitos entre população local, Subprefeitura e empresários (imobiliárias); fortalecimento da Associação das Mulheres do bairro, além do desejo fraterno de que o povo da Favela viva dignamente.

Relatamos agora a violação do direito à moradia: no dia 26 de novembro de 2007, a Subprefeitura apoiada pela polícia armada, adentrou a Favela com ordem de despejo imediato sob pena de desocupação por parte do poder público, com a justificativa de que a área é municipal e foi ocupada irregularmente ${ }^{4}$. No entanto, a Subprefeitura não garantia lugar para aqueles despejados isso causou medo e profunda insegurança nos moradores.

2 O Fórum Social Mundial (FSM) é um evento de âmbito mundial, organizado por movimentos sociais com objetivo de celebrar a diversidade, discutir temas relevantes e buscar alternativas que julgam adequadas para questões sociais.

3 Zonas Especiais de Interesse Social - As ZEIS são um dos mecanismos de regularização fundiária, que consistem em áreas especialmente destinadas à produção e manutenção de habitação de interesse social. Essas zonas têm por objetivo incorporar os espaços urbanos clandestinos - favelas, assentamentos urbanos populares, loteamentos irregulares e cortiços - à "cidade legal" (Maniero e Pessoa, 2005, p. 11).

4 Prefeitura do Município de São Paulo. Subprefeitura do Ipiranga. Auto de Intimação n. 49214. Assinado por duas testemunhas. 
Segundo uma moradora que foi obrigada a assinar a ordem de despejo enviada pela Subprefeitura:

Foi na mentira de promessas enganosas que muita gente aqui assinou o documento. Até menor assinou! Eles tratam a gente é com mentira para conseguir as casas. Dá revolta sim, mas o que fazer? Não temos nada (Moradora da favela há 20 anos).

Até as palavras de uma criança, de cinco anos, nos chocaram e deram a dimensão do medo de não ter onde morar:

Tia, é verdade que vão tirar nós de nossa casa? É verdade? O que vão fazer com nós? Eu vou ficar sem casa? Vou ficar na rua? (Criança moradora da favela).

\section{Outro depoimento:}

É duro viver num lugar em que não somos considerados pessoa, gente. A gente já sofre por não ter onde morar e quando encontramos um lugarzinho temos que ouvir "precisamos limpar a cidade", o oficial de justiça falou. Então somos nós é que sujamos a cidade? Somos nós a sujeira? Querem limpar a cidade nos jogando onde? Dói muito ter que ouvir isso (Moradora da favela há vinte anos).

Presenciamos, por ocasião desse ato, além da violação do direito à moradia, o direito à segurança, justiça, liberdade, o direito de ser cidadão e, especialmente, o desrespeito às mulheres do local. Para explicar essa colocação, adotamos o conceito de gênero como referência, apesar de não nos aprofundarmos nesta discussão, chamamos a atenção para a violação dos direitos das mulheres, aspecto que demonstrou relações sociais marcadas pela diferenciação entre os sexos, ainda muito acirrada em nossa sociedade. A questão de gênero deve ser pontuada no processo que relatamos.

Resumidamente, podemos dizer que o conceito de gênero foi incorporado pelo feminismo e pela produção acadêmica sobre mulheres nos anos 1970 e, desde então, tem sido interpretado de formas distintas por diferentes correntes do feminismo. O uso ainda hoje mais freqüente do conceito é o proposto pelo feminismo da diferença (Carvalho, 1998), este rejeitou pressupostos do feminismo da igualdade, que afirmava que as únicas diferenças efetivamente existentes entre homens e mulheres são biológicosexuais, e que as demais diferenças observáveis são culturais.
Conforme Carvalho (1998) as teóricas e os teóricos da diferença assumem que o conceito de gênero remete a traços culturais femininos (ou, no pólo oposto, masculinos) construídos socialmente sobre a base biológica. Existiria, então, uma polarização binária entre os gêneros, em que a diferença é concebida como categoria central de análise, fundamental na definição de estratégias de ação (Hita, 1998).

Há também o caráter histórico das diferenças entre os gêneros e a própria construção social da percepção da diferença sexual (Scott, 1994; Carvalho,1998), cujo conceito de gênero, enfatiza as relações sociais entre os sexos, permitindo a apreensão de desigualdades entre homens e mulheres; um dos componentes centrais dessa desigualdade é a questão de poder (Safiotti, 1994; Scott, 1994). Segundo Ribeiro, (2007), a relação masculino/feminino não é algo dado, baseada exclusivamente em diferenças biológicas, mas se constrói ao longo do tempo, sendo apreendida como processo, sujeito a constantes mudanças e transformações.

Se assim o é, as ações desenvolvidas na favela Boqueirão, foram coordenada por mulheres, a maioria chefes de famílias, que participaram das ações sociais urbanas com presença expressiva, como não queremos incorrer no erro pontuado por Souza-Lobo (1991) "freqüentemente as análises ignoraram que os principais atores nos movimentos populares eram, de fato, atrizes", lembramos que foram as mulheres quem denunciaram os temas específicos à condição da mulher da favela, como direito à creche, saúde da mulher, sexualidade e contracepção e violência contra a mulher. A história da favela Boqueirão é também a da constituição das mulheres como sujeito coletivo, em que estas deixam a esfera privada e passam a atuar no espaço público, ou pelo menos tentam, tornando públicos temas até então confinados à esfera privada (Sarti, 1988; Giffin, 1991; Souza-Lobo, 1991).

Na discriminação de temas ligados à problemática da mulher ${ }^{5}$ da Favela Boqueirão, houve uma convergência, no nosso entendimento, com o movimento feminista ${ }^{6}$, há atuação feminina na Favela seja por seu papel na família, sua presença decisiva nos assuntos ligados à moradia e ao bairro, fortalecimento da tendência de formulação de propostas de ação, ressignificação das políticas públicas. A Associação das Mulheres do bairro passou a compor um locus que se constitui em espaço privilegiado na luta pela superação da desigualdade entre mulheres e homens, salvo as devidas proporções, na sociedade brasileira.

Podemos ainda afirmar que no debate sobre a questão de gênero há diferenças significativas que vão

5 A Constituição de 1988 também reflete a questão de gênero quando relembramos que a mobilização das mulheres, organizadas em torno da bandeira Constituinte pra valer tem que ter palavra de mulher, as mulheres estruturaram propostas para a nova Constituição, apresentadas ao Congresso Constituinte sob o título Carta das Mulheres Brasileiras (Costa, 1998).

6 O feminismo, diferentemente dos 'movimentos sociais com participação de mulheres', tinha como objetivo central a transformação da situação da mulher na sociedade, de forma a superar a desigualdade presente nas relações entre homens e mulheres. 
desde as abordagens relativas às políticas com foco na mulher; ênfase na eficiência e uma certa funcionalização da mulher, vista como um 'instrumento' do desenvolvimento; potencializadora de políticas públicas, até o efetivo papel que desempenham na comunidade, mesmo assim, não houve, por parte da Subprefeitura da Região Ipiranga, o menor respeito às mulheres no momento da ação de despejo, elas foram agredidas, desacatadas, humilhadas, presenciaram seus filhos em pânico diante da perspectiva de ficarem sem moradia; mas se posicionaram e iniciaram ações que repercutiram no impedimento efetivo da ação de despejo.

Diante dessa ação, se todos os direitos são violados, onde encontrar respaldo para sustentar o que Gadotti (2007, p.12) descreve como sendo a construção de um mundo melhor? A construção de uma cultura de Paz?

Busquemos resposta na única e indispensável possibilidade: a visão histórica e o sentido da práxis ${ }^{7}$. Talvez reviver o conquistado apoiado no vivido possa nos dar um norte na defesa dos direitos violados de todos os povos.

\section{Moradia, direitos humanos: uma perspectiva histórica}

Tudo se iniciou com a Declaração Universal dos Direitos Humanos (DUDH) que, segundo Guimarães (2004 p. 82), "nasceu no dia 10 de dezembro de 1948, proclamada solenemente pela Assembléia das Nações Unidas. Ela marcou um dos grandes momentos históricos do século XX", apesar de só ter sido gerada e publicada após graves conflitos, inúmeras atrocidades, mortes e total descartabilidade do ser humano na sociedade mundial. Segundo Guimarães (2004, p. 88),

a declaração dos Direitos Humanos teve como causa imediata a experiência das duas grandes guerras. As pessoas estavam chocadas, especialmente com o assassinato de milhões de judeus pelos nazistas e com as vítimas das bombas atômicas de Hiroshima e Nagasaki. Estes acontecimentos provocaram reações em todo o mundo: a humanidade queria ter certeza de que nada igual aconteceria novamente.

A historicidade do nascimento da DUDH ratifica que os direitos humanos são fundamentais a todos, sem quaisquer distinções de sexo, nacionalidade, etnia, cor da pele, faixa etária, classe social, profissão, condição de saúde física e mental, opinião política, religião, nível de instrução e julgamento moral. Entretanto, o que se destaca na fala de Guimarães é que o eixo principal e óbvio, da DUDH é o reconhecimento do direito à vida, sem o qual todos os demais direitos perderiam seu sentido.

Levando em conta a sucessão do tempo, por uma questão didática, pode-se dizer que os direitos humanos foram divididos em gerações, não no sentido biológico, do que nasce, cresce e morre, mas no sentido histórico, de uma superação com complementaridade, e que pode também ser entendida como dimensões. Resumidamente, a primeira geração, contemporânea das revoluções burguesas do final do século XVIII e de todo o século XIX, é aquela que concerne aos dos 'direitos civis' e das liberdades individuais, liberdades consagradas pelo liberalismo, quando o direito do cidadão dirige-se contra a opressão do Estado ou de poderes arbitrários, contra as perseguições políticas e religiosas, a liberdade de viver sem medo. Dessa importantíssima 'primeira geração', ou dimensão, constam os direitos de locomoção, de segurança e integridade física, de justiça, expressão e opinião, e de propriedade, resguardando-se direito à moradia. Essas liberdades surgem oficialmente nas Declarações de Direitos, documentos das revoluções burguesas do final do século XVIII (na França e nos Estados Unidos) e foram acolhidas em diversas Constituições de países do século XIX.

A 'segunda geração', que não abrange apenas os indivíduos, mas os grupos sociais, surge no início do século XX, na esteira das lutas operárias e do pensamento socialista na Europa Ocidental, explicitando-se, na prática, nas experiências da social-democracia, para consolidar-se, ao longo do século, nas formas do Estado do Bem-Estar Social. Refere-se ao conjunto dos direitos sociais, econômicos e culturais: os de caráter trabalhista, como salário justo, férias, previdência e seguridade social, e os de caráter social mais geral, independentemente de vínculo empregatício, como saúde, educação, habitação, acesso aos bens culturais etc. Em complemento às duas anteriores, a 'terceira geração' inclui os direitos coletivos da humanidade, como direito à paz, ao desenvolvimento, à autodeterminação dos povos, ao patrimônio científico, tecnológico e cultural da humanidade, ao meio ambiente ecologicamente preservado; são os direitos ditos de solidariedade planetária. De qualquer ângulo que se observe, essas gerações

7 Práxis é aqui compreendida como em Marx (1989), que é um movimento que possibilita a compreensão da realidade, que é efetivamente contraditória. A práxis originária é o trabalho humano e esse é a objetivação da subjetividade, fonte subjetiva de todo valor e de toda riqueza. E na medida em que o indivíduo não reconhece em cada objeto a subjetividade humana, está alienado. A produção material esclarece a práxis social e a história como auto-produções do homem por si mesmo. É pela práxis, atividade humana, real efetiva e transformadora, que o homem se humaniza. E para tanto - humanizar-se - o homem não pode permanecer em sua subjetividade, necessita objetivar-se, o que só pode ocorrer através da práxis. Compreendemos que a luta pela moradia desenvolvida na Favela Boqueirão é uma proposta de resistência, negação, e transformadora, assim como o conceito de práxis definido por Marx. 
mostram como continua viva a bandeira da revolução francesa: a liberdade, a igualdade e a fraternidade. A liberdade nos primeiros direitos civis e individuais, a igualdade nos direitos sociais, a fraternidade-solidariedade como responsabilidade social pelos mais fracos nos direitos da humanidade.

Este breve retrospecto histórico explica o porquê de trabalharmos com a questão da moradia 'para' e 'pelas' pessoas. Elas são portadoras de direitos, direitos humanos, que são fundamentais porque indispensáveis para uma vida com dignidade. Quando insistimos na questão da moradia, damos um novo sentido para essa luta: ela passa a dar corpo e alma a pastoral social ao representar 'dignidade humana'.

Aqui se faz importante esclarecermos o que entendemos por dignidade da pessoa humana. É fácil identificarmos um comportamento indigno. Por exemplo, a omissão de socorro nos hospitais, abandono dos idosos, agressão aos mendigos, às crianças de rua, aos desempregados, aos excluídos de toda sorte. São claras manifestações indignas ou indignidades. O contrário é o moralmente aceito, que indica algo superior, que, na esfera sobrenatural da revelação religiosa, seria algo que se aproxima da criação divina - do ser humano criado à imagem e semelhança do Criador (Boff).

O conceito de dignidade humana associa-se ao metafísico, àquilo que seria próprio da boa natureza humana, o que sempre promoveu várias discussões filosóficas que acabaram desembocando nas discussões sobre a essência da natureza humana. Independentemente dessas polêmicas, aqueles que são religiosos ou espiritualistas, ou aqueles que acreditam na afirmação de que todos somos irmãos na fraternidade, serão militantes em prol dos direitos das pessoas.

Distanciando-nos da visão religiosa ou metafísica, percebemos que os textos nacionais e internacionais em defesa dos direitos humanos explicam a dignidade pela própria transcendência do ser humano, ou seja, foi o homem que criou ele mesmo o Direito que deve ser respeitado. Estabelecendo formas de acordos sociais, o homem criou as formas da idéia de dignidade em grandes textos normativos que podem ser sintetizados no artigo $1^{\circ}$ da Declaração Internacional de Direitos Humanos de 1948: "todos os seres humanos nascem livres e iguais em dignidade e em direitos". Esta formulação decorre da própria reflexão do ser humano, que a ela chegou de uma maneira que é historicamente dada.

Esse ato (re)significou paradigmas e com eles mentalidades. Os direitos humanos estão profundamente ligados à essência e existência humana porque também são naturais e universais, independentemente de qualquer ato normativo. Eles valem para todos, são interdependentes e indivisíveis, não podem ser separados: se aceitarmos apenas os direitos individuais ou só os sociais, ou só os de defesa ambiental, viveremos uma incompletude.

Essas características têm de ser relembradas porque ainda temos no século XXI regimes políticos liberais que pregam a liberdade, mas descartam a obrigatoriedade dos direitos sociais. Nossas esperanças residem no fato de que os direitos humanos são históricos, reconhecidos e consagrados em determinados momentos, e que, por isso, é possível pensarmos que novos direitos ainda podem ser identificados e consolidados.

Num sentido mais amplo, a história da humanidade comprova a evolução da consciência dos direitos; na Bíblia, por exemplo, lemos casos de aceitação de sacrifícios humanos e de escravidão que foram superados com a atuação do próprio sujeito humano. Os liberais da América do Norte e do Sul conviviam com a posse de escravos, embora defendessem a liberdade e a igualdade de todos diante da lei, experiência que também foi superada. Hoje, diga-se que quase sem exceções, reconhecemos que existe uma consciência universal de que a escravidão, seja por que motivo for, é uma violação radical dos direitos humanos, assim como a exploração do trabalho infantil, a prostituição infantil, a dominação sobre as mulheres, as formas variadas de racismo e de discriminação por motivos religiosos, políticos, étnicos, sexuais, as questões relacionadas à moradia etc.

Os ainda existentes casos de escravidão, exclusão, racismo e discriminação são veementemente condenados pelas entidades mundiais de defesa dos direitos humanos e é neste grupo que nos incluímos, por fé e militância. É neste sentido que os Direitos humanos crescem em abrangência e em profundidade, até que se consolidem na consciência universal.

A reflexão de Piovesan (2008) também nos direciona a discussão sobre a dignidade da condição humana, sobretudo no espírito da DUDH (1948). Ela é mais contundente ao afirmar que o que inova a gramática desses direitos é a chamada concepção contemporânea de direitos humanos, marcada pela universalidade e indivisibilidade dos mesmos. Procurando compreender o conceito de universalidade e indivisibilidade, a autora descreve a primeira no momento em que a Declaração clama pela extensão universal dos direitos humanos, sob a crença de que a condição de pessoa é o requisito único para a titularidade de direitos, considerando o ser humano como um ser essencialmente moral, dotado de unidade existencial e dignidade, como valor intrínseco à condição humana. A segunda, por sua vez, é a garantia dos direitos civis e políticos, é condição para a observância dos direitos sociais, econômicos e culturais e vive-versa. Quando um conceito é violado, os demais também o são. Piovesan reforça nossos objetivos na luta pelo reconhecimento dos direitos das pessoas que moram na Favela Boqueirão, afinal os direitos humanos compõem uma unidade indivisível, interdependente e inter-relacionada, capaz de conjugar o catálogo de direitos sociais, econômicos e culturais (Piovesan, 2008, p. 9).

Buscando na DUDH o direito à moradia, bem como a universalidade e indivisibilidade dos direitos 
humanos, conforme afirmaram Piovesan (2008), Arruda (2003), Brandão (2002), encontramos no Art. 25:

Toda pessoa tem direito a um nível de vida suficiente para assegurar a sua saúde, seu bem-estar e o de sua família, especialmente para a alimentação, vestuário, 'moradia', cuidados médicos e serviços sociais necessários; tem direito à segurança, em caso de desemprego, doença, invalidez, viuvez, velhice ou em outros casos de perda dos meios de subsistência, graças a circunstâncias independentes de sua vontade (Souza, 1989 p. 30, grifo nosso).

Acrescente-se, ainda, que após a Declaração de 1948, outros instrumentos em defesa dos direitos humanos consolidaram-se. Tratados e Convenções trouxeram uma nova consciência em relação aos direitos humanos e uma forma justa de encarar suas violações. É importante que se frise, o Brasil é signatário de tudo o que foi estabelecido em termos de direitos:

[...] declarações e convenções internacionais ratificadas (aceitas) pelo Brasil, tais como a Declaração dos Direitos (1948), a Declaração do Progresso e Desenvolvimento Social (1969), a Declaração sobre Assentamentos Humanos de Vancouver (1976), a Declaração sobre o Direito ao Desenvolvimento (1986), a Agenda 21 (1992), a Agenda Habitat (1996), o Pacto Internacional dos Direitos Econômicos, Sociais e Culturais (1966), e a Convenção Sobre os Direitos da Criança (1989) também incluem o 'direito à moradia' como um direito humano fundamental a ser perseguido por todos (Maniero; Pessoa, 2005, p. 6, grifos nossos).

Ao discutir o Pacto Internacional sobre Direitos Econômicos, Sociais e Culturais, no livro $A$ afirmação histórica dos direitos humanos, Comparato (2007) confirma a importância do direito à moradia, entre outros, o que também foi reconhecido pelos Estados que assinaram o Pacto. Vejamos o destaque no Artigo 11:

Os Estados-Partes do presente Pacto reconhecem o direito de toda a pessoa a um nível de vida adequado para si próprio e sua família inclusive à alimentação, vestimenta, e 'moradia adequadas' assim como a uma melhoria contínua de suas condições de vida (Comparato, 2007, p. 353, grifos nossos).

Se no âmbito internacional o direito à moradia é instituído e assegurado à pessoa, no âmbito nacional ele também o é. Está confirmado pela Lei maior do País, na Constituição Federal (1988). Vejamos o que promulga a Constituição Federal (1988), Capítulo II dos Direitos Sociais, Artigo $6^{\circ}$, que contempla a redação da Emenda Constitucional n. 26, de 14 de fevereiro de 2000:

São direitos sociais a educação, a saúde, o trabalho, a 'moradia', o lazer, a segurança, a previdência social, a proteção à maternidade e à infância, a assistência aos desamparados, na forma desta Constituição (Brasil, 1988, Constituição, p. 12, grifos nossos).

A Constituição Brasileira no artigo 23, incisos IX e X, p. 25 e 26, estabelece que:

é de competência comum da União, dos Estados, do Distrito Federal e dos Municípios:

IX - promover programas de construção de moradias e a melhoria das condições habitacionais e de saneamento básico;

$\mathrm{X}$ - combater as causas da pobreza e os fatores de marginalização, promovendo a integração social dos setores desfavorecidos; $[\ldots]$.

Ainda a Constituição contempla, no Artigo $3^{\circ}$, inciso III, p. 3, erradicar a pobreza e a marginalização e reduzir as desigualdades sociais e regionais.

Como relatamos, mediante os artigos citados e da Emenda Constitucional n. 26/2000, há no Estado Brasileiro a garantia da moradia a toda pessoa.

Acreditamos que o definido na $\mathrm{CF} / 88$, tornouse importante instrumento na defesa e efetivação dos direitos humanos do País, entre eles o da moradia, que está incluso na lei. Todavia, esse direito torna-se invisível diante do descaso do poder público e, de forma crítica e pessoal, observamos a ausência de postura ética e moral na efetivação do mesmo.

Nossa sociedade, pelo menos a maioria dela, vive o resultado desse descaso que é traduzido pela má distribuição dos recursos, falta de interesse e respeito aos mais necessitados. A ausência de política habitacional, por exemplo, gera a não-garantia efetiva do que promulga a lei, os Tratados, as Declarações. Desrespeito aos cidadãos e à dignidade humana.

Em âmbito local a discussão sobre o direito à moradia também se faz presente. Ela tem sido conduzida pelo Ministério das Cidades - MCidades ${ }^{8}$. Este, por sua vez, determina que cada cidade da Federação construa o seu Estatuto da Cidade ${ }^{9}$, que deve combater as desigualdades sociais, transformando as cidades em espaços mais humanizados, ampliando o acesso da população à moradia, ao saneamento e ao transporte. Ao Ministério compete tratar da política de desenvol-

8 Ministério das cidades é um órgão do governo federal. O Ministério das Cidades, criado pelo presidente Luiz Inácio Lula da Silva em $1^{\circ}$ de janeiro de 2003, contemplou o combate às desigualdades sociais, transformando as cidades em espaços mais humanizados, ampliando o acesso da população à moradia, ao saneamento e ao transporte. Fonte: http://www.cidades.gov.br/ministerio-das-cidades/acesso em 19 de março de 2008. 9 Estatuto da Cidade - Lei Federal n. 10.257/01 - é o instrumento de regulamentação dos artigos 182 e 183 da Constituição Federal de 1988, contém as referências e institutos jurídicos e políticos básicos para a intervenção urbana. Fonte: http.:/www.scielo.br/scielo. 
vimento urbano e das políticas setoriais de habitação, saneamento ambiental, transporte urbano e trânsito.

O Ministério das Cidades deve promover novas políticas e novos sistemas que viabilizem o investimento coerente e integrado - público e privado - de modo a racionalizar os recursos de acordo com as prioridades e necessidades previstas em planos, indicadores de desempenho e posturas (nacionais/gerais e locais/específicas) definidos de forma democrática como se verá mais à frente. Espera-se, assim, eliminar os constantes desperdícios de recursos decorrentes da descontinuidade de projetos, desarticulação entre ações simultâneas e sucessivas, falta de integração intermunicipal, falta de controle social e público e desconhecimento das questões ambientais.

Cabe ao MCidades fortalecer as competências, não apenas por meio do financiamento de planos, projetos e obras, mas, especialmente, por apoiar a capacitação técnica de quadros da administração pública municipal ou dos agentes sociais locais. Essa capacitação envolve especialmente a modernização administrativa, em especial a atualização e o registro das informações municipais sobre o ambiente construído. $\mathrm{O}$ cadastro multifinalitário é uma ferramenta eficiente tanto para o planejamento urbano quanto para a política fiscal. Esses temas estão na base da autonomia municipal, mas mesmo tendo instituído o órgão competente para preservar e assegurar o direito a moradia, a realidade vivida no Estado de São Paulo tem deixado muito a desejar.

Maniero e Pessoa (2005) mediante um projeto do Centro de Direitos Humanos, São Paulo, elaboraram uma cartilha sobre Direitos Humanos intitulada 'Moradia e Direitos Humanos', que divulga os direitos como uma contribuição para a formação acadêmica dos estudantes de direito, para que eles possam conhecer, defender e realizar ações jurídicas no campo dos direitos humanos em prol da população deles carente e desprovida.

Aqui, então, é de nosso interesse destacar a referência sobre o direito à moradia:

Após 10 anos de discussões e elaborações, entrou em vigor em 10 de julho de 2001 o Estatuto da Cidade, que regulamenta os artigos 182 e 183 da Constituição Federal. Esta lei estabelece diretrizes gerais da política urbana; fornece instrumentos da política urbana (que são garantias para atingir o pleno desenvolvimento sustentável da cidade) e, conseqüentemente, do 'direito à moradia'.

\section{Diretrizes Gerais}

Garantia do direito a cidades sustentáveis, entendido como direito à terra urbana, à moradia, ao saneamento ambiental, à infra-estrutura urbana, ao transportes e aos serviços públicos, ao trabalho e ao lazer, para as presentes e futuras gerações; [...] (Maniero e Pessoa, p. 9, grifos nossos).

Como podemos observar, a DUDH, o Pacto Internacional, as Convenções em prol dos direitos huma- nos, a Constituição Federal (1988), o Ministério da Cidade, e a Cartilha sobre Direitos Humanos intitulada: Moradia e Direitos Humanos, asseguram e defendem os direitos fundamentais das pessoas, todos juntos proclamam, em bom tom, o caminho que deve ser seguido para a democratização e efetivação desses direitos.

Sabemos que todos esses documentos não garantem os direitos dos cidadãos, e foi na tentativa de continuar na luta que surge o Movimento dos Trabalhadores Sem Teto (MTST), em 1997, visando estruturar a reforma urbana e garantir moradia a todos os cidadãos. Está organizado nos municípios de Campinas e São Paulo, com um caráter social, político e sindical. Em 1997, o MST fez uma avaliação interna em que reconheceu que seria necessária uma atuação na cidade além de sua atuação no campo. Dessa constatação, duas opções de luta se abriram: trabalho e moradia.

O MTST assume o compromisso de lutar, ao lado dos excluídos urbanos, contra a lógica perversa das metrópoles brasileiras, pois, ao mesmo tempo que, sobram terra e habitações, faltam moradias. A especulação imobiliária transforma terra urbana em promessa de lucro e alimenta o processo de degradação humana, o caos urbano.

As famílias sem-teto não têm direitos, são o avesso da cidadania, isto é, são não-cidadãos, pois só têm obrigações como: votar, cumprir as leis, mas não lhes são garantidos os direitos básicos. Vivem como sombras nos semáforos, nas esquinas, nos bancos das praças, atrás de um prato de comida, um trocado. Enfrentam a indiferença, o preconceito, a violência policial, além de serem excluídas das decisões políticas que determinam os rumos da vida social. É por isso que o MTST tem como um dos seus objetivos o combate à máquina de produção de miséria nos centros urbanos. A ocupação de terra, trabalho de organização popular, é a principal forma de ação do movimento. Quando ocupam um latifúndio urbano ocioso, os sem-teto resistem contra a lógica difundida como natural de que pobre nasce, vive e morre oprimido. Essa mesma tática deve conduzir a militância daqueles que lutam pelo direito à moradia na favela Boqueirão: não aceitar a espoliação que muitos chamam de sina.

\section{Direito à moradia $x$ dignidade ameaçada: a práxis}

Em defesa da democratização e efetivação desses direitos, é que testemunhamos a violação do direito à moradia das pessoas que vivem na Favela Boqueirão. É notório que, nas favelas, nos loteamentos irregulares, nas palafitas, nas ocupações informais, nos cortiços, nas ruas, não há qualidade de vida e, muito menos, ações que recuperem esse direito. $\mathrm{O}$ que presenciamos 
é que quase tudo é improvisado, algo que gera uma população doente, humilhada com pouquíssimos recursos de vida digna. Concordamos com Moramoto e Baltrusis (1992), quando afirmam que 'a falta de moradia popular é sem dúvida um dos maiores problemas que a população carente enfrenta'. $\mathrm{Na}$ análise da práxis, importa saber o que dizem os moradores:

Estou morando na favela há doze anos. Saí do Ceará à procura de uma vida melhor aqui em São Paulo, mas a realidade aqui é outra, tudo muito caro, por isso é que viemos morar na favela, o aluguel é muito pesado para nós. Fico pensando como é triste a gente não ter um endereço, "não somos gente, não somos nada", sem moradia, sem casa somos pessoas sem identidade, sem endereço. É triste pensar e viver assim. A casa é tudo que uma pessoa deve ter (T.G.A - Moradora da Favela Boqueirão).

Temos que lutar sempre por moradia. Ela é o lugar aonde a gente chega cansada e repousa, mesmo sendo na favela, é bom ter um barraco onde a gente passa a chuva. Mas era bom ser uma casa boa. É bom lutar por moradia, todo mundo tem direito, por que só os ricos têm casa pra morar? A gente escuta que é direito de todo mundo, mas eu não vejo isso acontecer para nós na favela (E. S. M - Moradora da Favela Boqueirão).

Aqui na favela a gente não vive dignamente, não somos respeitados. Ter dignidade é ter um salário digno para a gente não precisar morar nos barracos de madeira, de lona ou em cima do córrego. É meus filhos poderem comer todos os dias. É não precisar pedir na vizinha um pouco de arroz. É desesperador não ter casa, não ter o pão de cada dia, não ter escola, só quem não tem sabe o que significa (S.A.R - Moradora da favela Boqueirão).

As pessoas da favela Boqueirão traduzem a necessidade de milhares de brasileiros. Todos têm seus direitos assegurados na forma fria de Leis, sem alma. Elas normatizam com uma mão, mas com a outra persistem que se abram as portas de uma dura realidade: "dia-a-dia mais difícil [...] sacrifício, cada vez mais...", como citamos na epígrafe, com a música Moradia, da Banda Elipse (2008).

Como podemos perceber, tudo é difícil para esta população, especialmente o acesso aos serviços públicos. O próprio Ministério das Cidades apresenta certos dados revelando o número da população de 'Sem Teto' no Brasil, mediante uma pesquisa feita pelo Instituto Brasileiro de Geografia e Estatística (IBGE), em 2004:

Brasil população - 180 milhões; Número de Municípios - 5.561; Déficit habitacional - 6,6 milhões de moradias; Água potável - 45 milhões de pessoas sem acesso; Esgoto - 83 milhões de pessoas sem acesso; Coleta de lixo -12 milhões de pessoas sem acesso (Fonte Ministé- rio das Cidades, 2004 BRASIL, grifos nossos). Fonte: IBGE (Ministério das Cidades, 2004).

$\mathrm{O}$ que resta para aquelas pessoas da favela Boqueirão? O que resta a quem acompanha, de perto, o drama diário dos desprovidos? É preciso ouvir os anseios, os temores dos que, a despeito de tudo, vão sobrevivendo:

O meu maior sonho é ter uma casa, que eu possa dizer que é minha. Que eu cuide dela, que eu possa receber meus parentes, meus amigos. Onde eu receba uma carta. Eu tenho medo é da violência, hoje está bom, mas há três anos atrás a gente via pessoas sendo torturadas, gente morta na porta das casas. Era terrível! Eu vivia com medo de deixar minhas crianças sozinhas para ir trabalhar (R.A - Moradora da Favela Boqueirão).

Eu tenho medo de acordar e receber um oficial de justiça com uma ordem de despejo, sem eu saber para onde ir com meus filhos. Todos da nossa casa trabalham, mas não deu ainda para comprarmos uma casa e sair da favela, este é meu sonho (G.A - Moradora da Favela Boqueirão).

A luta pelo direito à moradia deve somar-se a tantas outras, como disseram Gadotti (2007) e Guimarães (2004). Fazer com que ela se torne uma alternativa para a consolidação de uma sociedade mais justa e solidária, que ela amplie a articulação de um novo projeto de sociedade. Afinal, o que os moradores do Brasil, em especial, da favela Boqueirão pedem, é apenas o respeito ao que já está instituído.

\section{Conclusão \\ $O$ direito à moradia é ainda um direito embrionário}

O tema Direitos Humanos tem sido, na atualidade, objeto de inúmeros debates, muito embora, há vários séculos, os homens tenham consciência de que a pessoa humana tem direitos fundamentais, cujo respeito é indispensável para a sobrevivência do indivíduo em condições dignas e compatíveis com sua natureza.

Esses direitos fundamentais nascem com a pessoa e, por isso, não podem ser considerados como uma concessão do Estado. É por essa razão que, no preâmbulo da Declaração Universal dos Direitos do Homem (ONU-1948), não se diz que esse 'direitos' são outorgados ou mesmo reconhecidos, preferindo-se dizer que eles são proclamados, numa clara afirmação de que eles preexistem a todas as instituições políticas e sociais, não podendo, assim, ser retirados ou restringidos por essas instituições. Essa Proclamação dos Direi- 
tos Fundamentais da Pessoa Humana torna claro que as instituições governamentais devem proteger esses direitos contra qualquer ofensa.

Este quadro não é novo no tocante ao direito à moradia. É povoado de contradições que nos permitem dizer que a elite brasileira, formada em torno de valores autoritários e conservadores, produzem uma nação povoada por sem-terra, sem-teto, sem-renda, sem-cultura e educação, sem-trabalho e esperança.

É nesse sentido que podemos dizer que a cidadania não existe para milhões de brasileiros, excluídos das mais elementares condições de vida e submetidos às mais sórdidas das explorações. Além dos bairros chiques, na periferia propriamente dita, ou até mesmo encrustada no centro de bairros ricos, como é o caso da Favela Boqueirão, há loteamentos irregulares e imóveis superpovoados, em que muitas famílias dividem um mesmo espaço, pagam aluguéis exorbitantes, carecem de saneamento básico, urbanização e legalização de suas moradias.

Longe de caminhar para esta direção, as políticas públicas de recuperação e revalorização da cidade favorecem, sobretudo, a especulação. Ao longo da última década, a população da periferia de São Paulo cresceu num ritmo cinco vezes mais rápido do que o total da aglomeração, agravando uma situação já catastrófica e carregada de conflitos potenciais.

A crise da moradia continua a se intensificar no Brasil e em São Paulo, em junho de 2004, por exemplo, uma delegação conjunta das Nações Unidas e da Missão Nacional de observação ao direito da moradia percorreu o Brasil. Ela registrou denúncias graves relativas à brutalidade policial nas expulsões de imóveis e de terrenos ocupados e, em seu relatório, concluiu que os poderes públicos não tratam a moradia como um direito fundamental, mas como uma mercadoria. Isso é vergonhoso.

Um caminho proposto é acreditarmos nas mudanças e no poder que a população tem. A saída é lutarmos para a concretização das Políticas Públicas que englobam as Reformas Agrária e Urbana, o combate às desigualdades sociais, reforma trabalhista, flexibilização das políticas educacionais, política de Saneamento Ambiental, educação voltada à pessoa e não somente à competição exacerbada, proteção e defesa da vida e, acionar os tratados internacionais de proteção aos direitos humanos, quando um direito for violado, seja por parte da sociedade ou por parte do poder público. Essas são alternativas para mudar o sistema socioeconômico, tornando eficaz os direitos fundamentais da pessoa, possibilitando maior participação de todos no processo de melhoria da sociedade, fazendo com que o Estado cumpra sua função social.

Alertamos que é na Constituição de 1988, que há o reconhecimento notoriamente do direito à moradia adequada e a autorização da desapropriação de terre- nos e imóveis que não cumprem sua função social e, ainda, é o Poder Político que outorga este direito ao povo. Devemos nos utilizar desse instrumento legal enquanto houver a crise da moradia nas grandes cidades brasileiras.

Para garantir o direito à moradia da população da Favela Boqueirão, trabalhamos a fim de ajudá-los a tomar consciência de seus direitos, a organizaremse em Associação de Moradores para que possam ser, eles mesmos, mediadores entre o poder público e o povo. Eles devem tomar conhecimento do que lhes foi conferido pela Constituição de 1988, pela Declaração dos Direitos Humanos, pelo Estatuto da Cidade, entre outros, para que unidos possam defender seus direitos, ajudando, assim, a construção de uma sociedade inclusiva e participativa.

Para assegurar os Direitos Humanos, inerentes à dignidade da pessoa, é preciso garantir a prática da Justiça e da Paz. Pensamos que, a possibilidade de se concretizar tal fato se dê por um processo de desenvolvimento de uma consciência crítica da população dessa comunidade. Só então, o povo da favela poderá tornar-se resistente ao sistema político-econômico que afirma que todos têm direitos à vida digna, mas, contraditoriamente, gera carência, submissão, insegurança, corrupção, latifúndios, espaços ociosos, morte, poder institucionalizado e desordem planetária. Em oposição a tudo isso, nada melhor que investir na Formação Humana - acadêmica e popular - de tantos homens, mulheres e organizações, sensíveis que apontam as saídas, por meio da solidariedade, da fraternidade, da compaixão e por que não dizer, da verdadeira construção da cidadania. Este é um passo para desconstruirmos o status quo e gerarmos uma nova sociedade.

Como militante pelo direito à moradia, lembramos que ao montar seus barracos de lona preta num terreno vazio, essas famílias cortam a cerca nada imaginária que protege a concentração de riqueza e de terra nas mãos de poucos. Como religiosas que se dedicam à Pastoral Social, lembramos que aquele é um terreno de onde poucos esperam muito lucro, talvez a perspectiva fraterna possa ajudar a promover os direitos dos sem-teto e, quem sabe, plantar ali uma semente de cidadania.

\section{Referências}

ARRUDA, M. Humanizar o infra-humano: a formação do ser humano integral: homo evolutivo, práxis e economia solidária. Petrópolis: Vozes, 2003.

BRANDÃO, C. R. A educação como cultura. São Paulo: Mercado das Letras, 2002.

BRASIL, Constituição da República Federativa: promulgada em 
5 de outubro de 1988. São Paulo: Saraiva, 2000. (Edição atual e ampliada).

CARTILHA - Secretaria executiva do Conselho das cidades e Assessoria de comunicação do Ministério das Cidades, 2004.

CARVAlHO, Sônia Nahas de. Estatuto da Cidade, aspectos políticos e técnicos do plano diretor. Disponível em: <http:/www. scielo.br/scielo> Acesso em: 19 de mar. de 2008.

CARVALHO, Marília Pinto de. "Gênero e trabalho docente: em busca de um referencial teórico”. In: BRUSCHINI, Cristina; BUARQUE DE HOLLANDA, Heloísa (Orgs.). Horizontes plurais: novos estudos de gênero no Brasil. São Paulo: Editora 34/Fundação Carlos Chagas, 1998.

COMPARATO, Fábio Conder. A afirmação histórica dos direitos humanos. São Paulo: Saraiva, 2007.

COSTA, Ana Alice Alcântara. "Trajetória e perspectivas do feminismo para o próximo milênio". In: PASSOS, Elizete; ALVES, Ívia; MACEDO, Márcia. Metamorfoses: gênero nas perspectivas interdisciplinares. Salvador: UFBA, Núcleo de Estudos Interdisciplinares sobre a Mulher, 1998. p. 25-37.

GADOTTI, Moacir. Educar para um outro mundo possível. (1. ed). São Paulo: Publisher Brasil. 2007.

GIFFIN, Karen. "A mulher, a cidade e os programas sociais". In: IBAM. Mulher e politicas públicas. Rio de Janeiro: IBAM/ UNICEF, 1991. p. 169-186.

GUIMARAES, Marcelo Rezende. Um novo mundo é possível: dez razões para educar para a paz, praticar a tolerância, promover o diálogo inter-religioso, ser solidário, promover os direitos humanos. São Leopoldo: Sinodal, 2004.

HITA, Maria Gabriela. "Gênero, ação e sistema: a reinvenção dos sujeitos”. Lua Nova, n. 43, p.109-131, 1998.

MANIERO, Laura; PESSOA, João Paulo. Moradia e direitos humanos. Disponível em: <http://www.cdh.org.br/artigo/ cartilhas/CARTILHAMORADIA.pdf>. Acesso em: 18 de mar de 2008.

MARAmOTO, Getúlio; BALTRUSIS, Nelson. Direito à moradia: uma contribuição para o debate / Adriana Poci Palumbo, Márcia Accorci Pereira, organizadores. São Paulo: Paulinas 1992.

MATURANA, Humberto. Emoções e linguagem na educação e na política. Belo Horizonte: UFMG, 1998b.

PIOVESAN, Flávia. Coordenação geral. Código de direito internacional dos direitos humanos. São Paulo: DJP, 2008.

SARTI, Cynthia. Feminismo no Brasil: uma trajetória particular. Cadernos de Pesquisa, São Paulo, n. 34, p. 38-47, 1988.

SAFFIOTI, Heleieth I. B. "Violência de gênero no Brasil contemporâneo". In: SAFFIOTTI, Heleieth I. B.; MUÑOZVARGAS, Monica (Orgs.). Mulher brasileira é assim. Rio de Janeiro/Brasília: Rosa dos Tempos-NIPAS/UNICEF, p. 151-187, 1994.

SCOTT, Joan. Prefácio a "Gender and Politics of History". Cadernos Pagu, Campinas, n. 3, p.11-27, 1994.

SOUZA-LOBO, Elisabeth. A classe operária tem dois sexos: trabalho, dominação e resistência. São Paulo: Brasiliense, 1991.

SOUZA, Ari Herculano. Os Direitos humanos. São Paulo: Editora do Brasil, 1989.

\title{
Human Rights, Violence, Home: Threatened Dignity
}

\begin{abstract}
Human rights, in their nature and universality, are deeply linked to the essence of the human being. They are meant to everybody in this planet. The Universal Declaration of Human Rights legitimizes human rights in an attempt to provide social justice. The right to a dwelling-place is also consecrated in the Declaration, as well as in Conventions and in the Federal Constitution of Brazil (1988). In the governmental sector, it is present in the Ministry of Cities and in the Statute of the Cities. They guarantee to the person, by the force of law, the right to a dignified dwelling place. Nevertheless, in everyday life, reality is quite different. Millions of people have troubled relations with the public power, which generates problems, besides the massification of social inequality.
\end{abstract}

Key-words: human rights; violence; social exclusion; religious action; democratization.

Data de recebimento do artigo: 30-05-2008

Data de aprovação do artigo: 05-09-2008 